\title{
Considerações sobre o indigenismo no México e Peru: a construção da identidade nacional na perspectiva política e intelectual
}

Graziela Menezes de Jesus ${ }^{1}$

\section{Resumo:}

O indigenismo é um dos principais movimentos políticos e intelectuais da América Latina no século XX que atinge seu auge no contexto da formação das identidades nacionais latino-americanas, especialmente no México e nos países andinos. Nesse sentido, temos como objetivo apresentar algumas considerações sobre o indigenismo mexicano e peruano, visando a compreender o que há de comum nessas experiências, partindo da análise crítica da bibliografia que trata de suas diferentes manifestações. Defendemos que o conceito é multifacetado e se refere a um conjunto de representações do índio, que vão do conservadorismo até a perspectiva radical de esquerda.

Palavras-chave: Indigenismo, México, Peru

\begin{abstract}
:
Indigenism is one of the major intellectual and political movements in the twentieth century Latin America it reaches its height within the context of the construction of the Latin American national identity, specially in Mexico and in the Andean countries. Seen in these terms we try to present some considerations on the mexican and peruvian indigenism movement, in order to understand what their experiences have in common, on the basis of the critical analysis of the literature that deals with its different manifestations. We argue that this is a multifaceted concept which refers to a group of Indian representations ranging from the conservative to the radical left-wing perspective.
\end{abstract}

Keywords: Indigenism, Mexico, Peru

No final do século XIX e início do século XX, emergiu no cenário político e intelectual latino-americano a questão racial. A problemática foi construída partir da ideia de que a humanidade estava dividida em raça superior - brancos - e inferior -

\footnotetext{
${ }^{1}$ Doutoranda em História Social das Relações Políticas na Universidade Federal do Espírito Santo. Título da pesquisa: "No soy un aculturado": identidade nacional e indigenismo nas obras de José Maria Arguedas. Bolsista da CAPES. Email: grazimenezes17@gmail.com
}

Revista Eletrônica da ANPHLAC, n.12, p. 176-196, jan./jun. 2012.

http://revista.anphlac.org.br/index.php/revista 
negros e índios. Ao longo do século XIX, o paradigma sociobiológico ganhou força nas ciências sociais e tinha como premissa a afirmação da superioridade e inferioridade racial. Essa teoria fundamentou uma forma de racismo a partir de características fenotípicas e genotípicas, possibilitando a criação de um sistema de categorização e hierarquização entre os grupos raciais.

Nessa perspectiva, tanto os índios quanto os negros foram vistos como raça inferior (SUAREZ, 2006, p.4). No final do século XIX, essas teorias foram incorporadas ao discurso nacional, dando lugar a uma série de abordagens pessimistas em relação às possibilidades de desenvolvimento do continente latino-americano. Gómes Suarez nos lembra que a obra Ensayo sobre la desigualdad de las razas humanas, do francês Gobineau, foi importante para difundir a tese do racismo sociobiológico (Idem, p.5), bem como as ideias evolucionistas de Herbert Spencer, que também foram incorporadas pela intelectualidade latino-americana, principalmente por Juan Batista Alberdi e Domingo Faustino Sarmiento, dando lugar a uma série de abordagens pessimistas sobre a impossibilidade do progresso e modernização, devido a enorme quantidade de indígenas (Idem, 2006, p.6).

Nesse contexto, o Indigenismo emergiu e marcou profundamente a intelectualidade, as artes e os movimentos sociais latino-americanos do século XX. De acordo com Michel Baud, o indigenismo surgiu como um fenômeno intelectual originalmente latino-americano, associado ao contexto de formação das identidades nacionais e também como uma resposta às teorias raciais. O indigenismo, em sua concepção, serviu para imaginar o futuro latino-americano. (BAUD, 2003, p.41).

Baud afirma que o indigenismo foi um movimento político e literário, que tinha como objetivo a revalorização da cultura indígena e assimilação dos índios. Ele também destaca que as ações indigenistas se manifestaram de diversas formas, abarcando o campo da política e das artes, com tendências distintas, marcadas tanto pelo radicalismo de esquerda, quanto pelo conservadorismo (Idem, p.65).

Partindo de uma premissa semelhante, José Bengoa considera o indigenismo o movimento cultural e político latino-americano mais importante do século XX, uma vez que atingiu os romances, a pintura, o teatro, a música e a política (BENGOA, 2000, p.204). Para ele, o indigenismo possui três elementos centrais:

Revista Eletrônica da ANPHLAC, n.12, p. 176-196, jan./jun. 2012. http://revista.anphlac.org.br/index.php/revista 
(...) la denuncia de la opresión del indio, la búsqueda de políticas de superación de la situación indígena por el camino de su integración al conjunto de la sociedad y la manifestación, como consecuencia de lo anterior, del carácter mestizo, indoamericano, del continente. (2000, p.205)

De modo geral, o indigenismo teve muita força nos países andinos e no México (BAUD, 2003, p.40). Acreditamos que tal fato se deu em função da forte presença da população indígena nessas regiões e, nesse sentido, pretendemos apresentar algumas considerações teóricas sobre o indigenismo no México e no Peru.

Embora o nosso objetivo seja tratar do indigenismo como um movimento político e cultural do século XX, não podemos negligenciar que, para alguns estudiosos, a presença/manifestação do indigenismo se dá desde o início da colonização. $O$ antropólogo francês Henri Favre, em seu livro El indigenismo, estuda o movimento desde a célebre defesa de Bartolomeu de Las Casas, apontando os antecedentes coloniais dessa corrente, uma vez que foram criadas as Leis Índias, responsáveis pela conversão dos índios em súditos da Coroa espanhola (FAVRE, p.19).

Favre desenvolve seus argumentos, partindo da ideia de que a essência do indigenismo é a presença de uma opinião favorável ao índio. $\mathrm{O}$ autor destaca a mudança do papel social dos indígenas no período pós-colonial e, indubitavelmente, problematiza o racismo científico como ponto de partida para o apogeu da corrente. Favre afirma que, nesse sentido, as ideias indigenistas surgiram como uma proposta de miscigenação biológica, na qual, diferente do que o darwinismo social afirmava, a miscigenação da raça indígena com a raça branca seria positiva: "El mestizo es el hombre nuevo en que el pais tiende a proyectar su concepción totalizante del destino colectivo y a quien confia el estandarte de la nacionalidad" (Idem, p.40).

A abordagem de Favre é interessante porque converge para a afirmação de que a corrente indigenista foi um dos principais elementos utilizados pelos estados latinoamericanos para forjar as nacionalidades, conferindo aos indígenas um espaço de mestiço, não de índio (Idem, p.148). Mesmo inserindo o indigenismo numa perspectiva de longa duração, Favre não desconsidera a relevância das teorias racistas e do processo de formação das identidades nacionais, apontando assim um ponto de convergência para o entendimento do indigenismo.

Revista Eletrônica da ANPHLAC, n.12, p. 176-196, jan./jun. 2012. http://revista.anphlac.org.br/index.php/revista 
Se buscarmos uma compreensão sobre as diferentes possibilidades de entendimento do indigenismo, podemos, talvez, fazer duas afirmações: em primeiro lugar, ao estudar o movimento indigenista, devemos lembrar que tal termo refere-se a uma multiplicidade de ações, pensamentos e áreas de atuação; em segundo lugar, o indigenismo, enquanto movimento político e cultural, refere-se à formação das identidades nacionais latino-americanas, sendo assim importante estudá-lo como um fenômeno oriundo da relação entre Estado-Nação e as identidades indígenas que o compõem.

A história oficial conta que o México sempre foi um país indígena. A historiografia nacional ensina que, no período pré-hispânico, os astecas desenvolveram a maior civilização das Américas, e a data de fundação de Tenochtitlán - capital asteca em 1325 foi incorporada como o mito de fundação da sociedade mexicana, em uma narrativa composta por elementos como o heroísmo e a originalidade. $\mathrm{O}$ mito dizia que a cidade deveria ser construída no local em que os astecas - em seu período de migração - avistassem uma águia pousada sob um cacto, devorando a serpente. A imagem reveladora da fundação de Tenochtitlán foi incorporada a um dos maiores símbolos do Estado-Nação, a bandeira nacional.

Os astecas são apresentados como um povo que formou uma sociedade complexa, com uma estrutura fiscal e social altamente organizada, uma sociedade de líderes e guerreiros, que conseguiu ser reconhecida como a mais alta cultura da era précolombiana.

Por outro lado, a chegada dos espanhóis e a conquista das Américas representaram um rompimento histórico para o desenvolvimento das sociedades indígenas, uma vez que eles foram derrotados e submetidos à dominação. Entretanto, a historiografia nacionalista aborda esse processo como um encontro cultural entre brancos e índios, criando assim o mito de descendência da nação mexicana. A partir da mistura entre espanhóis e índios surge o mito da nação mestiça.

De acordo com Gutierrez Chong (2001), os livros relatam a miscigenação como o agente formador da população mexicana: "Si casi toda población tiene ancestros mestizos, es posible dar forma a la percepción de que los mexicanos constituyen una sola família” (p.111). Durante a colonização, é importante ressaltar, que o grupo étnico 
favorecido era o dos espanhóis; os mestiços só vão emergir enquanto grupo étnico dominante a partir da Revolução Mexicana de 1910 e da necessidade de se criar uma identidade mexicana que desse conta das diversidades do país .

Navarrete (2004) chama esse processo de conversão do mexicano em mestiço de ideologia da mestiçagem e afirma que, além de fundamentar a nova nação, o novo sistema de ideias possuía duas características essenciais para o contexto histórico em que ele foi lançado. A primeira característica foi o fato de que a mestiçagem serviu para fundamentar o poder das elites intelectuais e políticas, porque essa mestiçagem, que foi evocada como a solução para a questão nacional, não se referia à mistura racial, mas sim ao amálgama cultural (NAVARRETE, 2004, p.91).

A segunda característica está relacionada com transformação da mestiçagem em algo positivo. Alguns teóricos consideravam que a mestiçagem representava a degeneração racial ${ }^{2}$, entretanto, os ideólogos da mestiçagem mexicana defenderam a ideia de que o cruzamento racial poderia constituir uma raça melhorada ou, como diz Navarrete, pelo menos melhor que os índios (2004, p.92). Através da mestiçagem, o "problema indígena" seria eliminado, ao passo que a mestiçagem daria origem a um novo homem, que teria como principais características a inteligência do homem branco e a resistência dos indígenas (FAVRE, 1999, p.42).

Se sairmos das teias do discurso nacionalista, observamos que aos índios, que não se identificam com a mestiçagem, sobraram apenas os espaços nas estatísticas de pobreza e marginalização social, ou seja, os indígenas tornaram-se o grande problema da nação mestiça. O elemento índio passou a ser interpretado como um entrave à modernização, por isso, as chamadas políticas indigenistas são aclamadas pelo Estado e por seus intelectuais.

O indigenismo surgiu no contexto pós-Revolução Mexicana e se apresentou como um projeto social de modernização. Assimilar, integrar, incluir o indígena eram faces diferentes do projeto modernizador e, principalmente, da própria consolidação do Estado pós-revolução. $\mathrm{O}$ indigenismo ganhou força principalmente durante o governo de Lázaro Cárdenas.

\footnotetext{
${ }^{2}$ Gobineau entendia que as raças tendiam a se misturar. Contudo, em sua abordagem, ele interpretava essa mistura como um processo de perda da humanidade (FAVRE, 1999, p. 42).
}

Revista Eletrônica da ANPHLAC, n.12, p. 176-196, jan./jun. 2012. http://revista.anphlac.org.br/index.php/revista 
Durante la presidencia del general Lázaro Cárdenas surgieron instituciones modeladas por los antropólogos (en su más amplia acepción) para poner en práctica la parte que les tocaba dentro de la política integrativa (de integrar la nación) diseñada por los estadistas de la Revolución mexicana. Esas instituciones son: el Instituto Nacional Indigenista (INI), el Instituto Nacional de Antropología e Historia (INAH, hoy incorporado al Consejo Nacional para la Cultura y las Artes) y la Escuela Nacional de Antropología e Historia (ENAH, incorporada al INAH). Una figura dominó en aquellos momentos la práctica de la antropología como programa de gobierno para integrar a los pueblos indios: Alfonso Caso, arqueólogo, historiador, etnólogo y político. Asumiendo los parámetros del nacionalismo mexicano reformulado por la revolución, Caso diseñó la antropología como instrumento del nuevo Estado nacional para conseguir la modificación sustancial de los pueblos indios que permitiera su inclusión en la, así llamada, sociedad nacional. La ENAH debería preparar a los antropólogos para ese propósito, que desarrollarían desde el INI. La etnohistoria y la arqueología estarían dedicadas al conocimiento del pasado prehispánico y a demostrar el mestizaje como hilo conductor de la historia mexicana. Pero, además, este esquema estuvo animado por la convicción de que el pasado colonial era parte del presente mexicano: allí estaban los pueblos indios. Para que ese pasado dejase de ser realidad había la necesidad de eliminarlo no sólo por degradante, sino por ser un estorbo para lograr la plenitud de la nación mexicana. (PUIG, 2004, p.01)

Inicialmente, o indigenismo representou uma proposta de assimilação das identidades indígenas. Entretanto, com o desenvolvimento da antropologia crítica, surgiram propostas que modificaram a vida das comunidades de forma positiva, como o acesso às estradas, a alguns serviços de saúde e à educação. No México, os principais idealizadores do projeto indigenista - José Vasconcelos, Manuel Gamio, Alfonso Caso, Gonzalo Aguirre Beltrán - entendiam que tais medidas serviriam para promover a integração nacional e o progresso, através do convencimento pacífico.

De acordo com Guillermo Palacios, o auge do indigenismo se deu entre 1920 e 1945, quando diversos grupos de intelectuais mexicanos foram incorporados formal ou informalmente ao Estado mexicano pós-revolucionário (PALACIOS, 2010, p.583). Palacios apresenta como hipóteses as ideias de que o desenvolvimento das ciências sociais mexicanas, durante esse período, esteve intimamente relacionado com os projetos sociais do regime pós-revolucionário e com o fato de que os intelectuais se apresentaram como mediadores culturais, que deveriam aproximar dois universos: o urbano e o rural (Idem, p.585).

Foi nesse contexto que se destacaram duas figuras centrais da intelectualidade mexicana: Manuel Gamio e José Vasconcelos. Gamio pode ser considerado o pai das ciências sociais no México (Idem, p.589) e o fundador do indigenismo mexicano. Sua

Revista Eletrônica da ANPHLAC, n.12, p. 176-196, jan./jun. 2012.

http://revista.anphlac.org.br/index.php/revista 
obra Forjando patria: pro-nacionalismo (1916) é fundamental para compreender seu pensamento e, principalmente, as bases do projeto de identidade nacional mexicano.

\begin{abstract}
"La verdadera nacionalidad", escribió Gamio, es por definición homogénea, y cumple con tres condiciones: primero "unidad étnica en la mayoría de la población, es decir, que sus individuos pertenecen a la misma raza o a tipos étnicos muy cercanos entre si”; segundo, "esa mayoría posee y usa un idioma común, sin perjuicio de poder contar con otros idiomas o dialectos secundarios"; y tercero "los diversos elementos, clases o grupo sociales ostentan manifestaciones culturales del mismo carácter esencial por más que difieran en aspecto e intensidad de acuerdo con las especiales condiciones económicas y de desarrollo físico e intelectual de dichos grupos". (GAMIO apud KOURÍ, 2010, p.426)
\end{abstract}

A tese de Gamio tinha como pressuposto a necessidade de ampliar estudos científicos voltados para a aplicação no mundo agrário e foi uma importante base para a articulação entre o Estado e os intelectuais mexicanos (PALACIOS, 2010, p.589). Em termos mais específicos, a obra Forjando Patria, apontava os caminhos da modernidade nas comunidades rurais e indígenas, dentro de uma perspectiva de assimilação desses grupos (Idem, p.589), ou seja, a construção da nação era viável dentro de uma perspectiva de homogeneidade. A assimilação dos povos indígenas e das comunidades rurais se daria a partir da educação e da adoção do mestiço como símbolo étnico da identidade nacional.

A base de formação desses jovens que participaram ativamente da construção do Estado pós-revolucionário foi o Ateneo de la Juventud, fundado em 1909, às vésperas da revolução (GARCIADIEGO, 2010, p.32). O papel do Ateneo foi dúbio: se, por um lado, formava jovens provenientes das elites porfiristas, por outro, também foi identificado com o processo revolucionário, uma vez que rompeu com o darwinismo social, o positivismo e o evolucionismo (Idem, ibidem), inaugurando uma nova fase de produção política e cultural no México.

José Vasconcelos foi um desses jovens formado pelo Ateneo, e sua atuação foi fundamental para dar impulso a esse projeto modernizador. Seu trabalho como reitor da Universidad Nacional e fundador da Secretariá de Educación Pública foi essencial para implementar um projeto de educação popular, que não apenas visava à alfabetização, mas também foi um esforço para fomentar aquilo que era chamado de "alta cultura",

Revista Eletrônica da ANPHLAC, n.12, p. 176-196, jan./jun. 2012.

http://revista.anphlac.org.br/index.php/revista 
incluindo a introdução de clássicos da literatura nos programas educacionais (GARCIADIEGO, 2010, p.35).

Embora seu trabalho tenha sido marcado por altos e baixos, temos que assinalar que a política cultural de Vasconcelos proporcionou um grande desenvolvimento do setor artístico e cultural no México, realizado conjuntamente com a vontade de integrar os setores rurais e indígenas.

O fomento da cultura e das artes no contexto pós-revolucionário foi pautado por uma tentativa de valorização do popular e da identidade nacional proposta pelo Estado. José Vasconcelos incentivou a relação dos intelectuais com o Estado, principalmente no que diz respeito aos pintores, que ganharam os muros dos prédios públicos e encomendas oficiais (GELADO, 2006, p.90). Índios, camponeses, a Virgem de Guadalupe, a Revolução Mexicana e seus ícones passaram a ilustrar os edifícios públicos, cumprindo não só a tarefa didática de educar através da imagem, como também inauguraram um dos principais movimentos artísticos latino-americanos: o muralismo.

A contribuição de Vasconcelos também se deu no campo da produção intelectual. A obra La raza cósmica, lançada em 1925, trazia à tona o debate racista do século XIX, porém com uma premissa distinta e fundamental: diferente das teorias de Spencer, Vasconcelos evocou Mendel para defender a mestiçagem racial como forma de melhorar todas as raças (SUAREZ, 2006, p.6). A mestiçagem era vista como a solução do problema nacional, entretanto, seu significado se modificou, passando a representar um amálgama de culturas, não de raças. $\mathrm{O}$ índio portava a identidade fundadora da nação mexicana, porém, era preciso dar a ele os elementos necessários para seu desenvolvimento como cidadão de um Estado mestiço, com uma identidade ocidental, católica e falante de espanhol.

A tarefa educacional foi fundamental para integrar as comunidades rurais e indígenas ao padrão de identidade que estava sendo construído. A partir de 1940, o Estado mexicano passou a implementar, com mais dedicação, uma série de políticas indigenistas para melhorar e modernizar as comunidades. A ideia de que faltavam estudos sobre essas questões, anteriormente defendida por Gamio, ganhou cada vez

Revista Eletrônica da ANPHLAC, n.12, p. 176-196, jan./jun. 2012. http://revista.anphlac.org.br/index.php/revista 
mais força e espaço na antropologia mexicana. Aos poucos, a antropologia no México passou a ter, quase que exclusivamente, o índio como objeto.

\begin{abstract}
El foro fundacional integracionista, como política indigenista de los estados, fue el Primer Congreso Interamericano Indigenista, celebrado en la ciudad de Páztcuaro (Michoacán) en 1940, desde el que destacados antropólogos, como Aguirre Beltrán, trabajaron para darle fundamento teórico y sentido práctico. Pensaban integrar al indio en la identidad nacional, por la vía de la ciudadanía individual.

El indigenismo no vislumbraba una vuelta al pasado precolombino, buscaba un punto de apoyo para construir un futuro en ruptura con Europa. El apogeo del movimiento indigenista se sitúa entre 1920 y 1970, abanderada por los estados intervencionistas y asistenciales, que querían llevar a cabo un proyecto nacional. El indigenismo no es la manifestación del pensamiento indígena sino una reflexión criolla y mestiza sobre el mismo. (Idem, p.12)
\end{abstract}

Aguirre Béltran foi um dos principais antropólogos indigenistas do México e, mesmo reconhecendo os êxitos e fracassos dos projetos que o antecedeu, destacou-se não só pelos seus inúmeros estudos, mas também pela defesa da antropologia aplicada. Seus estudos sobre o processo de aculturação e as zonas de refúgio são fundamentais para compreender a história da antropologia latino-americana e o indigenismo mexicano.

Ao longo de sua trajetória, Aguirre Béltran encontrou diversos opositores, principalmente na antropologia crítica que observava em sua obra e em seu trabalho elementos que poderiam provocar a eliminação da cultura indígena no México. Em um debate com Angel Palerm, Aguirre Béltran reafirmou suas convicções, afirmando que “(...) la absorción de los valores indios por parte de la cultura nacional implica la supervivencia - no la aniquilación cultural - de esos valores en el proceso irreversible de aculturación que contrae la formación de un Estado nacional (...)"(BÉLTRAN, 1983, p.199).

Para ele a defesa do indigenismo era a defesa de uma sociedade integrada, na qual o termo aculturação não tinha um significado negativo, nem era sinônimo de eliminação de um grupo étnico, mas sim o resultado de trocas interétnicas.

$\mathrm{O}$ debate indigenista também marcou a intelectualidade peruana do século $\mathrm{XX}$, porém, com características distintas. Inicialmente, podemos afirmar que uma das principais diferenças parte da relação entre o Estado e os intelectuais. No México, a Revolução deu o tom do indigenismo e inaugurou uma relação duradoura entre os intelectuais e as políticas indigenistas. No Peru, a ausência de uma revolução com

Revista Eletrônica da ANPHLAC, n.12, p. 176-196, jan./jun. 2012.

http://revista.anphlac.org.br/index.php/revista 
caráter popular gerou um indigenismo mais combativo, muitas vezes com ideias que priorizavam o conflito e, principalmente, um indigenismo de base marxista que pensava o índio como o sujeito da revolução.

É importante destacar que, assim como no México, o indigenismo também foi uma resposta às teorias racistas e apareceu no contexto de formação da identidade nacional peruana, matizado, obviamente, por suas questões internas. Carlos Iván Degregori afirma que o indigenismo peruano serviu para questionar a visão excludente que deixava os povos indígenas fora da comunidade nacional imaginada (DEGREGORI, 2008, p.28). Sendo assim, ele entendia que o indigenismo era essencial para conferir aos indígenas seu lugar na nação peruana. Devemos levar em consideração que o caráter reivindicativo assinalado por Degregori não elimina o paternalismo, nem tampouco a construção de uma identidade homogênea, uma vez que, como no caso mexicano, também estamos lidando com políticas estatais de desenvolvimento e com um discurso intelectual produzido para os índios e não por índios.

Para Karen Sanders, a construção da nação peruana era algo complexo, uma vez que, assim como no México, o Peru tinha a tarefa de articular a memória e a sobrevivência do passado indígena com a herança colonial (1997, p.163). Os primeiros debates a respeito de uma identidade nacional peruana surgiram no final do século XVIII, a partir da Sociedad Economica de Amigos de Lima e de periódicos como o Mercurio Peruano (SANDERS, 1997, p.163). Os membros desse grupo estavam inseridos numa tradição, chamada por David Brading de "patriotismo criollo", na qual a identidade patriótica surgiu a partir do ressentimento em relação aos espanhóis.

Assim como Benedict Anderson (1989), Brading acredita que a identidade foi fomentada pela viagem dos funcionários criollos, circunscritos a um mundo americano, no qual o fato de terem nascido na América os condenava a uma diferença em relação aos peninsulares (1991, p.420). Nesse contexto, os primeiros indícios de uma identidade nacional estavam mais relacionados a uma dissociação da Espanha, do que com um debate interno, em cada um dos novos Estados que foram formados.

Sanders afirma que o sentido da nação peruana foi moldado pelos criollos a partir das heranças coloniais. A autora argumenta que, por mais que alguns grupos estivessem preocupados com uma nacionalidade independente, a maioria considerava

Revista Eletrônica da ANPHLAC, n.12, p. 176-196, jan./jun. 2012. http://revista.anphlac.org.br/index.php/revista 
importante manter os laços imperiais, uma vez que a concepção de pátria como terra dos pais, foi um importante componente nesse primeiro debate (1997, p.165).

O momento mais crítico do debate sobre identidade nacional no Peru ocorreu no início do século XX, no contexto posterior à Guerra do Pacífico (1879-1883). Com a queda de riquezas geradas pela exploração do guano, o salitre converteu-se na principal opção de substituto econômico no Peru; entretanto, a derrota ocasionou a transferência de parte da região produtora de salitre para o Chile, provocando um aprofundamento da crise social, econômica, política (BURGA, 2005, p.164) e a ascensão de um modelo de Estado cada vez mais voltado para a herança hispânica.

A guerra contra o Chile impulsionou o patriotismo peruano e demonstrou a necessidade de consolidar o Estado e principalmente a nação. Nesse contexto, o governo de Cáceres foi considerado o iniciador do período nacional, ou seja, a construção de um projeto nacional que ultrapassou o patriotismo criollo (Idem, Ibidem).

O debate iniciado durante essa época foi fundamental para a construção da identidade nacional peruana e, mais, foi importante na consolidação da ideia de que um projeto nacional homogêneo era inviável porque o Peru estava dividido em dois: Lima, que representava a costa e a cultura herdada pelos e espanhóis, e Cusco, região serrana e base da cultura indígena.

Provavelmente, o primeiro ícone do indigenismo peruano foi Manuel González Prada. Suas ideias se destacam no contexto pós-Guerra do Pacífico, quando afirmou que o Peru perdeu a guerra porque não tinha um projeto de integração das comunidades indígenas e, consequentemente, era uma nação dividida, na qual os índios não eram cidadãos, mas sim servos (URIARTE, 1998). Devemos lembrar que, embora Gonzaléz Prada seja considerado o grande precursor do indigenismo peruano, não podemos desconsiderar que, entre 1909 e 1916, minoritária e isoladamente, Dora Mayer, Pedro Zulen e Joaquín Capelo tentaram apoiar as reivindicações e denúncias indígenas através da Asociación Pro-Indígena.

A denúncia de Gonzaléz Prada foi absorvida por uma parte da intelectualidade peruana que, nas primeiras décadas do século XX, contou com Valcárcel e Mariátegui para levar adiante a denúncia da condição do índio. Em 1927, Valcárcel lança a obra Tempestad en los Andes, marcada por um discurso claro de defesa do indígena e da

Revista Eletrônica da ANPHLAC, n.12, p. 176-196, jan./jun. 2012. http://revista.anphlac.org.br/index.php/revista 
cultura andina. Para ele, os espanhóis foram responsáveis pela interrupção do desenvolvimento dos povos andinos, uma vez que os índios foram submetidos a uma lógica de poder desigual que residia na propriedade de terras (BAUD, 2003, p.44). Em sua defesa intelectual, chegou a afirmar que a verdadeira essência da nacionalidade peruana residia no índio, defendendo também, a ideia de Cusco como capital do Peru (URIARTE, 1998).

Embora no plano das ideias, Valcárcel tenha sido um defensor radical da cultural indígena, no que se refere a sua atuação profissional, notamos uma política integracionista que muito se assemelha a de José Vasconcelos. Em 1945, ele foi nomeado Ministro da Educação e, em sua gestão, foi criado o Instituto de Etnología y Arqueología de la Universidad de San Marcos. O instituto produziu inúmeras pesquisas sobre as comunidades indígenas e realizou diversos projetos voltados para o desenvolvimento técnico e cultural nos Andes (DEGREGORI, 2008, p.32). Ao longo de seu envolvimento com as políticas públicas, Valcárcel dedicou-se à investigação do passado pré-colombiano e à tarefa de desenvolver a antropologia no Peru, mostrando que, assim como no México, os antropólogos peruanos viveram anos de um casamento feliz com Estado.

Nesse ponto, é interessante lembrar que Valcárcel apareceu no cenário intelectual como um defensor radical dos indígenas e, aos poucos, foi abandonando os ideais de Tempestad en los Andes, para assumir a defesa do passado pré-colombiano. Sua produção intelectual foi contemporânea a de Mariátegui e, em várias ocasiões, os dois trabalharam juntos. Entretanto, Mariátegui nunca saiu da condição de intelectual de esquerda, nem tampouco atuou junto ao Estado.

De modo geral, Maríategui é lembrado como um dos primeiros marxistas latinoamericanos. No decorrer de sua trajetória, atuou como membro e fundador do Partido Comunista Peruano, foi jornalista, crítico literário e criador da revista Amauta. Em sua obra mais importante, Siete ensayos de interpretación de la realidad peruana, analisou a questão indígena peruana como uma questão econômica, a partir de conceitos centrais do marxismo como modo de produção e alienação.

Mariátegui utilizou o termo indigenista numa perspectiva marxista e não abordou a questão indígena como um problema racial, mas sim como um problema 
econômico. Para ele, a causa da opressão do índio residia na concentração de terras gerada pela colonização. Ele defendia a sociedade incaica e entendia que, entre os incas, vigorava um modo de produção socialista que foi abortado pela colonização. Ele acreditava que era fundamental incorporar o índio ao projeto de nação, uma vez que o Estado peruano privilegiou a herança hispânica (FIGUEIREDO, 2010, p.78). Nesse sentido, recusava o indigenismo que fazia apologia ao passado incaico e, em suas obras, buscava defender o índio do presente. Dizia Mariátegui:

\begin{abstract}
Os indigenistas revolucionários, em lugar de um platônico amor ao passado incaico, manifestam uma ativa e concreta solidariedade com o índio de hoje. Esse indigenismo não sonha com utópicas restaurações. Sente o passado como uma raiz, mas não como um programa. A sua concepção da história e de seus fenômenos é realista e moderna. Não ignora nem esquece nenhum dos fatos históricos que, nestes quatro séculos, modificaram, junto com a realidade do Peru, a realidade do mundo. (MARIÁTEGUI, 1982, p.106)
\end{abstract}

Seus posicionamentos também foram importantes para definir a literatura indigenista, tendo em vista que, no campo cultural, o indigenismo literário peruano foi um movimento tão forte quanto o muralismo mexicano. Em Siete Ensaios de interpretación de la realidad peruana, ele afirma que literatura indigenista é essencialmente uma produção crítica realizada por não índios, tendo como contexto o mundo indígena. Mariátegui aponta que essa é a principal característica do movimento, uma que vez que, se os textos fossem produzidos por indígenas, chamaríamos de literatura indígena, não indigenista. Mariátegui também foi um defensor da tese do dualismo e afirmava:

En el Perú el problema de la unidad es mucho más hondo, porque no hay aquí que resolver una pluralidad de tradiciones locales o regionales sino una dualidad de raza, de lengua y de sentimiento, nacida de la invasión y conquista del Perú autóctono por una raza extranjera que no ha podido fusionarse con la raza indígena ni eliminarla ni absorberla. (MARIÁTEGUI, 2008, p.74)

O dualismo cultural foi uma saída para as questões de identidade nacional que se colocava na época. Diante da dificuldade do Estado de articular uma "peruanidade", os intelectuais do início do século XX criaram um sistema de representação pautado nas diferenças entre os dois principais grupos étnicos que compunham a sociedade peruana.

Revista Eletrônica da ANPHLAC, n.12, p. 176-196, jan./jun. 2012. http://revista.anphlac.org.br/index.php/revista 
A obra de José Maria Arguedas colabora com esse debate, construindo representações da sociedade peruana a partir desse universo de relações conflituosas entre as identidades étnicas pertencentes à identidade nacional, explorando um cenário que remete à própria vivência do escritor.

Com uma produção bibliográfica que inclui sete livros de contos, seis romances, cinco textos etnográficos, dois poemas e três traduções de relatos colhidos em quéchua para o espanhol, Arguedas destacou-se por tratar, em todas essas obras, da temática indígena. A leitura e análise da vasta obra de José Maria Arguedas coloca-nos diante dos dilemas da formação dos Estados nacionais na América Latina. Tais dilemas incluíam a discussão da integração e da aculturação dos sujeitos étnicos, bem como políticas modernizadoras, que eram entendidas como promoção da industrialização, da educação e do Estado liberal. Em suas obras, observamos a presença do cenário andino, o indígena como protagonista, a exploração do mundo mítico e a utilização de poemas e canções em quéchua, como uma tentativa de dar mais força ao seu relato.

\begin{abstract}
Arguedas defendió activamente la revalorización de la cultura indígena. Su conocimiento en quechua le confirió una posición especial dentro del movimiento indigenista, que más que hablar con la población india hablaba en su favor. (BAUD, 2003, p.76)
\end{abstract}

Nesse sentido, mais uma vez, vemos como a corrente indigenista está atrelada aos processos de formação dos Estados nacionais latino-americanos, num contexto em que a identidade indígena era interpretada de forma negativa, em função do pensamento racista do século XIX. Em seu texto, Razón de ser del indigenismo en Peru, Arguedas defende que o indigenismo é importante porque não só denuncia a condição do indígena, como também demonstra as possibilidades humanas dos índios que haviam sido, comumente, associadas a uma série de elementos negativos como a servidão e o vício alcoólico (ARGUEDAS, 1977, p.196).

A história de Arguedas é repleta de contradições, pois, embora seja frequentemente lembrado como um continuador da obra de Mariátegui $^{3}$, teve uma atuação política semelhante à de Valcárcel. Arguedas trabalhou no Ministério da Educação, foi chefe do Instituto de Estudos Etnológicos no Museu de Cultura Peruana,

\footnotetext{
${ }^{3}$ Alberto Flores Galindo na obra Buscando um Inca dedica-se a essa hipótese, mostrando como Arguedas desenvolve e amadurece os argumentos de Mariátegui.
}

Revista Eletrônica da ANPHLAC, n.12, p. 176-196, jan./jun. 2012. http://revista.anphlac.org.br/index.php/revista 
Catedrático de Etnologia da Universidade de São Marcos, além de Secretário do Comitê Interamericano de Folclore. As ações de Arguedas como etnólogo foram polêmicas, uma vez que se filiava politicamente ao indigenismo, mas, aos poucos, seus estudos caminharam para a defesa de uma perspectiva multicultura, que só foi popularizada academicamente cerca de quinze anos após sua morte (DEGREGORI, 2008, p.39), mostrando que, no final da década de 1960, o indigenismo já estava perdendo seu fôlego.

De modo geral, podemos pensar que o desenvolvimento do indigenismo esteve atrelado ao crescimento da antropologia como ciência na América Latina. Com o surgimento de institutos voltados para resolver a questão indígena, fortemente amparados pelo Estado para desenvolver suas pesquisas, os índios foram o foco dos estudos antropológicos dos anos 1920 aos anos 1960, e esse processo pode ser verificado tanto no México quanto no Peru.

No final da década de 1960, os temas foram se diversificando: estudos urbanos, estudos de imigração e, principalmente, as teorias econômicas que abordavam a dependência da América Latina. Se pensarmos que, nesse período, os indígenas começaram um processo de organização política, podemos entender que a crise do indigenismo também derivou da ausência de necessidade desse outro que antes falava pelos índios.

De modo geral, é possível afirmar que o indigenismo nunca existiu como um movimento único e coeso, por essa razão, podemos dizer que não tratamos aqui do indigenismo, mas sim de indigenismos. Da vertente radical de Mariátegui até as políticas integracionistas de Gamio, Vasconcelos e Valcárcel, encontramos diferentes representações do índio. De Arguedas a Aguirre Béltran, observamos duas grandes viradas intelectuais: uma que constrói positivamente a ideia de aculturação, e outra que, aos poucos, entende que a nacionalidade não reside apenas em brancos e índios; entretanto, ambos são considerados indigenistas.

Mesmo diante da complexidade do termo indigenismo, podemos ousar apontar alguns elementos que são comuns às experiências relatadas e possibilitam o entendimento do indigenismo como um movimento intelectual que não se restringe apenas ao México e ao Peru, embora nesses países tenha sido mais marcante: o

Revista Eletrônica da ANPHLAC, n.12, p. 176-196, jan./jun. 2012. http://revista.anphlac.org.br/index.php/revista 
indigenismo foi um movimento intelectual que emergiu no cenário latino-americano, no contexto de formação das identidades nacionais. Entre suas características, destacamos que o índio era apenas o objeto da questão, não era nem o interlocutor, nem o produtor do discurso indigenista, uma vez que um dos objetivos centrais do indigenismo era forjar uma identidade nacional positiva, na qual os elementos da cultura indígena seriam absorvidos pelo Estado, na tentativa de superar as teorias racistas do século XIX.

Do ponto de vista das comunidades indígenas, o indigenismo representou um ataque às suas identidades, embora também tenha fornecido os instrumentos que iriam possibilitar a reorganização dos indígenas e o surgimento do indianismo.

Christian Gros cita alguns elementos que abalaram a organização e a estrutura das comunidades indígenas, no contexto do indigenismo e de sua crise: a crise de produção das pequenas propriedades; o alto crescimento demográfico, dando às comunidades ameaçadas de extinção a possibilidade de estruturar um futuro diferente; a dialética de inclusão e exclusão sofrida pelas comunidades indígenas das terras baixas; mais acesso à educação formal e à informação, facilitando o processo de formação de uma elite indígena; a intervenção de atores de fora das comunidades, atuando como mediadores entre as comunidades e o mundo exterior; e o crescimento do direito positivo internacional (GROS, 1998, p.185-7).

Entre as décadas de 1960 e 1970, tradicionalmente, a questão indígena na América Latina era dividida em dois grandes grupos: o dos camponeses indígenas, interpretados como a maioria e como um grupo de cultura geralmente sincrética. e o grupo dos indígenas ditos isolados. $\mathrm{O}$ aparecimento desses grupos deveu-se à expansão comercial e econômica que ocorreu de diversas formas e maneiras, pressionando a região de fronteira entre os grupos. Nesse contexto, os grupos tiveram necessidade de se reorganizar, não só para defender suas identidades, mas também o seu direito territorial.

O surgimento de um novo setor indígena ampliou a pauta política dos camponeses indígenas, acrescentando à luta por terras temas como autonomia, autogestão, relação do território indígena com o meio ambiente, entre outros. A conjunção desses fatores teve como um dos seus maiores êxitos a formação de um novo dirigente indígena.

Revista Eletrônica da ANPHLAC, n.12, p. 176-196, jan./jun. 2012. http://revista.anphlac.org.br/index.php/revista 
O novo dirigente indígena, em muitos casos, possui educação superior e tem como principal objetivo trabalhar com a questão das diferenças entre a cultura ocidental e a cultura indígena. Nesse sentido, a força desse dirigente reside no fato de ele ter condições de conhecer e manipular os símbolos ocidentais e, ao mesmo tempo, usá-los na distinção que o torna indígena. Além disso, as novas lideranças trabalham com uma perspectiva dinâmica das identidades étnicas, recriando-as no contexto atual.

José Bengoa afirma que, nos anos sessenta, a maioria dos dirigentes indígenas era camponês. Suas principais demandas eram a reforma agrária, educação, estradas e apoio para o desenvolvimento das comunidades rurais. Esses dirigentes portavam a cultura indígena, na maioria das vezes, não possuía uma educação formal e seu contato com o mundo urbano dava-se através das lutas políticas (2000, p.82).

Gutiérrez Chong aponta que, além dos dirigentes, também surge a figura do intelectual étnico, com três preocupações gerais: primeira, uma tendência discursiva a elogiar o passado; segunda, uma capacidade para denunciar as condições de marginalização étnica; e, terceira, uma consciência da necessidade dos índios de se ocupar em seus assuntos e seu destino (CHONG, 2001, p.156).

A principal tarefa desses intelectuais índios era a de recuperar positivamente os símbolos culturais que outrora foram utilizados com o objetivo de formar uma indianidade ligada à construção dos Estados nacionais. Concomitantemente, também era tarefa dessa intelectualidade dar voz aos grupos étnicos, uma vez que, historicamente, sua consciência, seus interesses e necessidades foram falados com outra voz, em outra perspectiva. Ou seja, as diferentes formas de manifestação do indigenismo também podem ser interpretadas como um silenciamento dos indígenas.

A partir da década de noventa, quando a trajetória da emergência indígena coincidiu com o fim da guerra fria e o aniversário dos 500 anos da chegada de Cristóvão Colombo à América, esse processo ganhou mais destaque. Enquanto a Espanha e a Igreja Católica celebraram a colonização e evangelização do solo americano, grupos indígenas aproveitaram a oportunidade para manifestar "500 anos de Resistência Indígena", portanto, um efeito contrário ao proposto pelas autoridades. Para Bengoa, foi o contexto necessário e adequado para que emergissem novas identidades indígenas, novos discursos sobre etnicidade, novas organizações e novos movimentos (2000, p.88).

Revista Eletrônica da ANPHLAC, n.12, p. 176-196, jan./jun. 2012. http://revista.anphlac.org.br/index.php/revista 
As declarações dos movimentos indígenas pela América Latina assinalaram um novo momento na história desses povos. Eles não só falaram das práticas genocidas e etnocidas que ocorreram no momento da chegada dos colonizadores, como também afirmaram que o período do pós-independência não representou mudanças significativas em relação ao período colonial:

\begin{abstract}
La concepción de indio que surge en la Colonia y que lo caracteriza como ser inferior y diferente al blanco europeo se sigue manteniendo. Las prácticas indigenistas que propugnaron la "redención del indio" a través de su integración a la sociedad nacional, no han resuelto los problemas fundamentais de nuestros pueblos. (PROGRAMA DA CONAIE apud BENGOA, 2000, p.91)
\end{abstract}

Em termos de prática política e consciência étnica, a fala da CONAIE (Confederación de Nacionalidades Indígenas del Equador) inaugurou, para os movimentos indígenas latino-americanos, o discurso de continuidade histórica, baseado no caráter radical da afirmação de 500 anos de exploração. As celebrações dos 500 anos foram marcadas não só por festas promovidas pelos governos locais, mas também por mobilizações e resistência das populações indígenas.

Além dessas manifestações, a década de 1990 também foi marcada por levantes indígenas em alguns países na América Latina, como o levantamento equatoriano, ocorrido entre maio e junho de 1990, que trouxe para a pauta política elementos regionais e nacionais. O discurso de continuidade histórica deu aos indígenas argumentos fundamentais para sua luta, principalmente no que se refere à questão da luta pela dignidade e da luta contra a discriminação social. Atualmente, o protagonismo das políticas indigenistas foram substituídos pelos movimentos sociais indígenas, permitindo aos índios constituir organizações próprias de formação e influenciar os espaços de tomada de decisão sobre seu futuro.

Independente dos erros e acertos das políticas indigenistas, é fato que o indigenismo marcou a política latino-americana do século $\mathrm{XX}$, e, a partir de suas considerações e ações. foram articuladas várias identidades nacionais que passaram a ser contestadas pelos movimentos sociais indígenas contemporâneos, evidenciando que os indigenismos e suas conseqüências ainda são relevantes para compreender a história da América Latina.

Revista Eletrônica da ANPHLAC, n.12, p. 176-196, jan./jun. 2012. http://revista.anphlac.org.br/index.php/revista 


\section{Referências Bibliográficas}

ANDERSON, Benedict R. Nação e consciência nacional. São Paulo: Ática, 1989.

ARGUEDAS, José Maria. Razón de ser del indigenismo en el Peru. In: ARGUEDAS, José Maria. Formación de una cultura nacional indoamericana. $2^{\mathrm{a}} \mathrm{ed}$. México: Siglo Veinteuno Editores, 1977. p.189-197.

BAUD, Micheil. Intelectuales y sus utopías: indigenismo y imaginación de América Latina. Amsterdam: CEDLA, 2003.

BELTRÁN, Gonzalo Aguirre. Indigenismo en México: confrontación de problemas e PALERM, Angél. In: MEDINA, A; GARCIA MORA, C. (orgs). La quiebra política de la antropología social en México (Antología de una polémica) I. La impugnación. México: Universidad Nacional Autónoma de México, 1983, p. 195 - 226.

BENGOA, José. La emergencia indígena en América Latina. México: FCE, 2000.

BRADING, David. The first America. The Spanish monarchy. Creole patriots, and the liberal state 1492-1867. Cambridge: Cambridge University Press, 1991.

BURGA, Manuel. La historia y los historiadores en el Peru. Lima: Fondo Editorial de la UNMSM, 2005.

CHONG, Natividad Gutiérrez. Mitos nacionalistas e identidades étnicas los intelectuales indígenas y el Estado mexicano. México: PYV, 2001.

DEGREGORI, Carlos Iván. Dilemas y tendencias en la antropología peruana: del paradigma indigenista al paradigma intercultural. In: ; LÓPEZ, Pablo Sandoval. Saberes periféricos: ensayos sobre la antropología en América Latina. Lima: IEP, 2008. p.19-72.

FAVRE, Henri. El Indigenismo. México: FCE, 1998.

FIGUEIREDO, Eurídice. Representações de etnicidade: perspectivas interamericanas de literatura e cultura. Rio de Janeiro: 7 Letras, 2010.

GARCIADIEGO, Javier. Los intelectuales y la Revolución Mexicana. In: ALTAMIRANO, Carlos (Dir.). Historia de los intelectuales en América Latina II: los avatares de la "ciudad letrada" en el siglo XX. Buenos Aires: Katz Editores, 2010. p.3144.

Revista Eletrônica da ANPHLAC, n.12, p. 176-196, jan./jun. 2012. http://revista.anphlac.org.br/index.php/revista 
GELADO, Viviana. Poéticas da transgressão: vanguarda e cultura popular nos anos 20 na América Latina. Rio de Janeiro: 7 Letras, 2006.

GROS, Christian. El movimiento indígena: del nacional-populismo al neoliberalismo. In: KÖNIG, Hans-Joachim (Ed.). El indio como sujeto y objeto de la historia latinoamericana: pasado y presente. Frankfurt/Main; Madrid: Iberoamericana; Vervuert, 1998. p.185-187.

KOURÍ, Emilio. Manuel Gamio y el indigenismo de la Revolución Mexicana. In: ALTAMIRANO, Carlos (Dir.). Historia de los intelectuales en América Latina II: Los avatares de la "ciudad letrada" en el siglo XX. Buenos Aires: Katz Editores, 2010. p.419-432.

MARIÁTEGUI, José Carlos. Política. São Paulo: Ática, 1982.

. 7 ensayos de interpretación de la realidad peruana. Lima:

Librería Editorial Minerva, 2008.

NAVARRETE, Frederico. Las relaciones interétnicas en México. México: Universidad Nacional Autónoma de México, 2004.

PALACIOS, G. Intelectuales, poder revolucionario y ciencias sociales en México (19201940). In: ALTAMIRANO, Carlos (Dir.). Historia de los intelectuales en América Latina II: Los avatares de la "ciudad letrada" en el siglo XX. Buenos Aires: Katz Editores, 2010. p.583-605.

PALERM, Angel. Respuesta. In: MEDINA, A.; MORA, C. García (Orgs.). La quiebra política de la antropología social en México (Antología de una polémica). I. La impugnación. México: Universidad Nacional Autónoma de México, 1983. p.195 a 226. POLAR, Antonio Cornejo. Literatura y sociedad en el Perú: la novela indigenista. $2^{\mathrm{a}} \mathrm{ed}$. Lima: CELACP, 2005.

PUIG, Andrés Fábregas. Los pueblos índios y el nacionalismo mexicano. In: Revista de la Universidad de Guadalajara, México, vol.13, 2004. Disponível em: <http:// www. cge.udg.mx/revistaudg/rug13/lospueblos.html>. Acesso em 20 de dezembro de 2005.

SANDERS, Karen. Nación y tradición: discursos em torno a la nación peruana (18851930). Lima: Fondo de Cultura Económica, 1997.

Revista Eletrônica da ANPHLAC, n.12, p. 176-196, jan./jun. 2012. http://revista.anphlac.org.br/index.php/revista 
SUÁREZ, Águeda Gómez. Identidades colectivas y discursos sobre el sujeto indigena. In. AIBR. Revista de Antropología Ibéroamericana, $\mathrm{n}^{\mathrm{o}}$ 41, 2005. Disponível em: $<$ http://www.aibr.org/antropologia/aibr/>. Acesso em 20 de abril de 2006.

URIARTE, Urpi Montoya. Hispanismo e indigenismo: o dualismo cultural no pensamento social peruano (1900-1930). Uma revisão necessária. Revista de Antropologia, São Paulo, vol.41, n.1, 1998. Disponível em $<$ http://www.scielo.br/scielo.php?script=sci_arttext\&pid=S0034$77011998000100005 \& \operatorname{lng}=$ pt\&nrm=iso $>$. Acesso em 16 de junho de 2010.

Revista Eletrônica da ANPHLAC, n.12, p. 176-196, jan./jun. 2012. http://revista.anphlac.org.br/index.php/revista 